\title{
Technologies for Digital Modeling of Spatial Information About the Area for Agricultural Production
}

\author{
Elena Sazonova ${ }^{1}$, Veronica Borisova ${ }^{1}$, Sergey Terentyev ${ }^{1}$, Olga Kramlikh $^{2, *}$, and Irina \\ Sidorenkova ${ }^{3}$ \\ ${ }^{1}$ Smolensk State Agricultural Academy, 214000 Smolensk, Russia \\ ${ }^{2}$ Financial University affiliated to the Government of the Russian Federation, Smolensk Branch, \\ 214018 Smolensk, Russia \\ ${ }^{3}$ Smolensk branch of G.V. Plekhanov REU, 214030 Smolensk, Russia
}

\begin{abstract}
One of the topical trends in the development of agriculture in the Russian Federation is digitalization and automation of methods for processing spatial information about various land resources. The main element of the implementation of this direction in practice can be considered a three-dimensional digital terrain model. This model allows solving many problems in the field of land management, in particular, such as analyzing the surface of the terrain in order to determine its suitability for agricultural production. Despite a number of existing problems in this area, an automated digital land management system will enable public authorities to implement an integrated and systematic approach to management, that is, to more efficiently use the land resources, influence the land market, as well as attract the investments and create the necessary conditions. for sustainable development of the territory.
\end{abstract}

\section{Introduction}

There is a global need to increase the area of cultivated land, which should be suitable for farming. But at the same time, there is a proportional decrease in the fertility of land resources both in Russia and abroad - gradual degradation, erosion, salinization, waterlogging, flat soil washout, desertification and other negative impacts. These natural consequences have a very negative impact on the life of society, and can lead to global environmental problems. So every year countries lose millions of hectares of fertile land. Experts and world scientists note that practically all reserves for increasing the volume of agricultural production have already been exhausted [1, p. 505]. Given that the world's population is constantly increasing and the area of cultivated land is reducing, all this can lead to an imminent food shortage.

In modern conditions, many problems of the development and effective functioning of agriculture in the Russian Federation are determined. The main ones include a constant reduction in the area of fertile land, deterioration in the quality of land due to the impact of

\footnotetext{
* Corresponding author: kramlikh.olga@yandex.ru
} 
negative technogenic processes, a decrease in the overall level of efficiency of cultivation of land resources, etc. In connection with the regional characteristics of the listed problems, it becomes necessary to change the qualitative approach to the zoning of agricultural lands. However, at present, there are very few really high-quality technologies for zoning the agricultural areas [7].

The solution of pressing urgent problems in the field of agricultural land resources management must be accompanied by a comprehensive analysis of the relief surface. This analysis will determine the degree of suitability of land for the production of agricultural crops, as well as conduct constant monitoring of the state of the area.

Additionally, we note that the land administration system includes a number of subcategories that shall be studied separately. Accordingly, from time to time, some issues of land management arise, in the solution of which, a different degree of knowledge is determined. There are many scientific works that are devoted to the problems of effective land management [2, p. 280]. In Russia, special attention should be paid to scientific works that describe the possibilities of rational use of land resources using digital modeling technologies. In Russia, these scientists include Bondina N.N., Bochko T.F., Varlamova AA, Volkova S.N., Gavryushina N.V., Gerasimenko V.P., Goncharova M.V., Denisova N.S. , Dokuchaeva V.V., Zhurkina I.G., Kirik D.A., Kochurov B.I., Shaldunova N.P., and others.

In order to increase efficiency in making management decisions on the rational and efficient use of agricultural land, it is recommended to resort to digital modeling technologies. The data obtained using digital terrain models can be used to solve a wide range of problems in the engineering, technical and management areas of agriculture in the region of presence. The analysis of the results obtained by means of digital modeling of available land resources can be used to optimize the crop production to increase the profits and rationalize the costs $[3$, p. 6].

\section{Materials and Methods}

The following methods were used as a methodological background for the study: analytical, system analysis, method of guided classifications, cartographic, zoning methods, methods of spatial GIS analysis, as well as methods of processing geodetic measurements and data obtained using unmanned technologies.

\section{Results and Discussion}

The results of the study can be applied in the practical activities of the agricultural producers. In particular, this concerns the process of developing new projects to optimize the management of land and property complexes [4].

When implementing digital modeling in agriculture, technologies that use data from GPS receivers can be used. They are installed directly on agricultural machinery. At the same time, GPS-receivers must have high spatial and temporal resolutions, as well as support the formats of vector maps of the area [5]. Map data contains many layers - vector maps, each of which must have specific attribute information. Attributive information, in turn, contains the qualitative and quantitative characteristics of the area.

When compiling a vector elevation map using the classification of a dense point cloud, contour lines of the terrain should be built, which will determine the exact boundaries of agricultural lands in an automated mode. With the help of terrain survey, tree and shrub plantations (outliers) are clearly displayed on the vector maps. In addition, the contours of water and road objects, various facilities, structures and buildings are clearly defined. The 
obtained data can be used to form a consolidated vector map of the territory included in the study.

Automation of image processing is realized through the technology of the built-in Tools Draw polygons module in the specialized Micro Station / Terra Scan software [2].

In the course of the study, the classification of topographic objects has been carried out according to seven separate classes of points. On the basis of the developed classification, the "Tools Draw polygons" module can build vector contours exactly along the boundaries of the passage of individual classes of points (Figure 1).

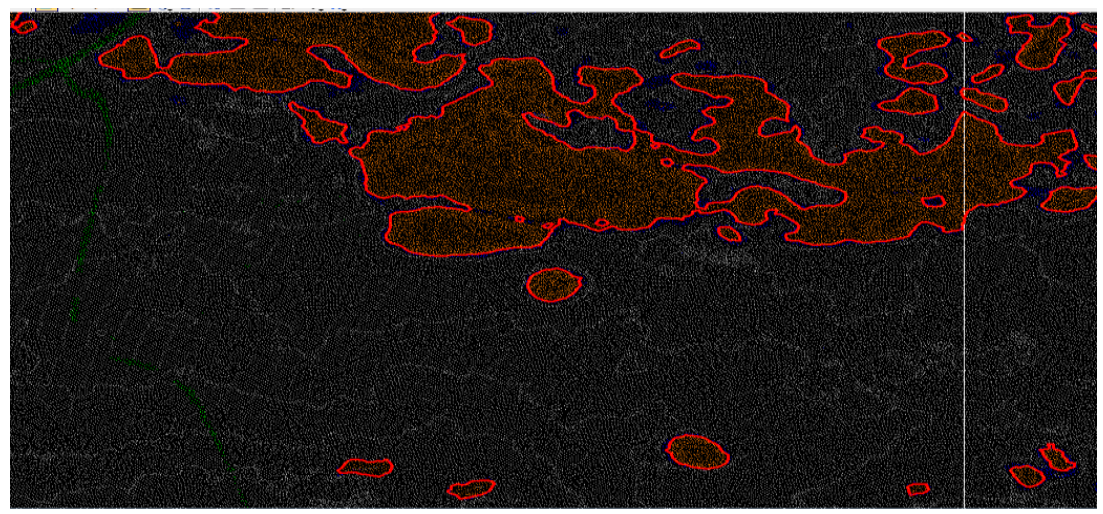

Fig. 1. Vector outlines of tree and shrub vegetation of the study area

According to the data shown in Figure 1, the polylines of the site pass exactly along the border of the "High-stemmed forests" class of a dense cloud of points, which makes it possible to determine the exact area of the object under study, occupied by various vegetation. In addition to calculating the area occupied by trees and shrubs, areas of land that are suitable for agriculture can also be determined. The interactive module "Tools Draw polygons" can also determine the areas occupied by the settlements, buildings, structures, warehouses, as well as water bodies.

As a result, after all components will have been included in the experiment, a thematically prepared vector map of the area will be constructed at the second stage of the developed algorithm. This digital map will serve as a basis for a quantitative and qualitative analytical assessment of fertile agricultural lands. In the framework of Table 1, the intermediate results of the second stage of the algorithm being developed are presented, that is, objects will be drawn on the map by the number of image points and the area of agricultural land, shown in Figure 1.

Table 1. The calculated data are the results of the second stage of the developed algorithm.

\begin{tabular}{|c|c|c|c|}
\hline Name of the class & Number of points & $\begin{array}{l}\text { Estimated area, } \\
\mathbf{m}^{2}\end{array}$ & $\begin{array}{c}\text { Share in the } \\
\text { total } \\
\text { composition }\end{array}$ \\
\hline Agricultural land & $3,184,688$ & $14,084,728.68$ & 64.77 \\
\hline High forest & $2,066,964$ & $6,690,666.66$ & 30.77 \\
\hline Bushes & 233,626 & $571,290.29$ & 2.63 \\
\hline Water body & 71,068 & $315,644.17$ & 1.45 \\
\hline Motor road & 22,124 & $77,354.54$ & 0.36 \\
\hline Capital construction projects & 1,684 & $5,682.08$ & 0.03 \\
\hline Lows & 314 & - & 0.00 \\
\hline Total & $5,580,468$ & $21,745,366.33$ & 100 \\
\hline
\end{tabular}

Having analyzed the results of Table 1, we come to the conclusion that agricultural lands in the selected study object have a small contour, and also have a large number of 
inclusions. The size of the inclusions varies from a square meter to several thousand square meters. Note that more than $30 \%\left(7.2 \mathrm{~km}^{2}\right)$ of the total area of the analyzed site is occupied by shrubs and high forests. For the full use of this site for the production of agricultural products, it is necessary to clear it of these types of vegetation.

It is necessary to additionally assess the characteristics of agricultural land areas. The location of objects in the space of a land plot (fertile plot) determines the quality and efficiency of land use for agricultural production. Most agricultural production processes are dependent on the availability and passability of the cultivated land space due to the need for the constant movement of both working equipment and finished products.

The basis for the assessment and analysis of the spatial characteristics inherent to the object under study is based primarily on production relationships. They allow to take into account the direct and indirect impact on the final result of agricultural production. The efficiency of agricultural production directly depends on the relative costs of material and labor costs. These costs lie in the need to travel long distances and natural barriers to agricultural production. In addition, agricultural producers need to constantly provide access to all the necessary resources. These primarily include the location of land resources, the total size of land use, and features of the terrain. At the same time, one cannot ignore the indirect impact on the final financial result of agricultural activity. External indirect spatial factors include various manifestations of a natural and climatic nature, as well as various social and economic manifestations in the course of production activities.

The results of the second stage are the values of the most significant coefficients obtained for the study carried out within the framework of the developed algorithm for using digital modeling technologies for agricultural lands. These include the spatial characteristics of lands - the coefficients of compactness, spatial distance, dissection.

The coefficient of compactness $\left(\mathrm{K}_{\mathrm{k}}\right)$ is an indicator that characterizes the level of fracture of the boundaries of the land plot. It is calculated by dividing the actual perimeter of a land plot by the perimeter of a conventional square of the same area. If the coefficient of compactness approaches 1 , then the agricultural land can be recognized as favorable for production.

The spatial distance factor $\left(\mathrm{K}_{\mathrm{y}}\right)$ is an indicator that characterizes the level of land use in terms of the extent of the distance that is required to transport the products. This indicator is calculated by dividing the sum of the distances of the average distance of lands along landuse roads and the distance from the delivery center by an indicator $1.7 \times \mathrm{P}^{1 / 2}$, where $\mathrm{P}$ is the perimeter of a square of the same area.

Number of permeable intervals of land $\left(\mathrm{K}_{\mathrm{r}}\right)$ is an indicator that determines the level of land dissection by ravines or gullies. It is calculated by dividing the total length of the hydrographic network by the agricultural land use area.

At the third stage of the implementation of the algorithm for the analysis and digital modeling of agricultural lands, the main spatial characteristics of the lands of the research object have been calculated. According to the results obtained using a digital elevation model, we have that there are practically no intersections of agricultural land borders by ravines, gullies and other objects of the hydrographic network. That is, the number of permeable intervals of the lands of the research object is practically zero.

At the same time, using a digital model for studying the land surface of the research object, the coefficient of compactness of the boundaries of productive lands has been automatically calculated. It turned out to be less than 1 , which suggests that this territory is favorable for agricultural producers.

When modeling the terrain of the object of study, the level of inclusions has also been assessed. For a detailed analysis of the territory, orthophotomap technologies have been used [6, p. 97]. With its help, digital terrain models have been built, which made it possible to further establish the level of inclusions within the boundaries of fertile land. In the study 
area, there is a varied level of inclusions in shape and area of tree and shrub occurrences, undersized shrubs, and water bodies. The reasons for the spread of this kind of inclusions on the territory of agricultural land are the natural and climatic features of the region.

The coefficient of spatial distance on the territory of the study object has been within the boundaries below the average value of the indicator. That is, in this agricultural area, there are areas with a spatial structure, which will cause additional financial costs in the production of the products.

Reducing the level of expenses or keeping them at a level lower than that of competitors is one of the main goals for the agricultural producers.

\section{Conclusion}

1. Technologies for digital modeling of spatial information about the terrain can be applied in any territory suitable for agricultural production.

2. With the help of digital modeling technology, the degree of forestedness of the territory, the level of its compactness, spatial remoteness, dissection, and dissemination can be calculated.

3. The research results can be applied in the practical activities of the agricultural producers in the development of new projects to optimize the management of land and property complexes.

4. The use of digital modeling technology will help reduce the level of costs of agricultural producers, increase their income, that is, ensure the proper level of competitiveness of these organizations.

\section{References}

1. I.V. Sidorenkova, V.L. Borisova, E.A. Sazonova, Challenges of the digital economy: results and new trends. Collection of papers of the II All-Russian scientific-practical conference, 505 (2019)

2. E.A. Sazonova, I.V. Sidorenkova, The main directions and forms of consumer cooperation development in Europe and Asia: experience, problems, prospects. Materials of the international scientific and practical conference in the framework of the annual Chayanov readings, 275 (2016)

3. V.A. Panfilov, Bulletin of Russian agricultural science, 1, 4 (2020)

4. E.V. Lavrova, O.Yu. Kramlikh, S.V. Kovaleva, Scientific Review, 16, 50 (2017)

5. Departmental project "Digital Agriculture": official publication, 48 (2019)

6. V.L. Borisova, O.Yu. Kramlikh, Digital region: experience, competencies, projects, Proceedings of the II International Scientific and Practical Conference, 95 (2019)

7. O.Yu. Kramlikh, S.V. Kovaleva, Food industry, 7, 32 (2016) 